\title{
Optimization of the Operation of a Municipal Wastewater Treatment Plant with Hydrocotyle ranunculoides
}

\author{
Rebeca Quispe', Mishel Soto', Ever Ingaruca', Wilfredo Bulege ${ }^{2 *}$, María Custodio' \\ 1 Universidad Nacional del Centro del Perú, High Mountain Research Center, Av. Mariscal Castilla № 3989-4089, \\ Huancayo, Perú \\ 2 Universidad Continental, Environmental Sustainability Research Center, Av. San Carlos 1980, Huancayo, Perú \\ * Corresponding author's e-mail: wbulege@continental.edu.pe
}

\begin{abstract}
The objective of the study was to optimize the operation of the municipal wastewater treatment plant (WWTP) of the Sicaya district with Hydrocotyle ranunculoides. The relative growth rate of the macrophyte was determined, in addition to the relationship between the population growth area and the final weight according to the number of days elapsed. Medium fences were implemented and the tributary and effluent of the WWTP were characterized physicochemically and microbiologically. The results of the characterization corresponding to the tributary were as follows: $616 \mathrm{mg}$ of TSS/L, $109.2 \mathrm{mg}$ of BOD $/ \mathrm{L}, 305.4 \mathrm{mg}$ of COD/L, $30.3 \mathrm{mg}$ of oils and fats/L and $3500000 \mathrm{NMP}$ of thermotolerant coliforms $/ 100 \mathrm{ml}$. Owing to the implementation of two medium grids, large suspended solids were retained. The highest efficiency of COD removal with respect to the growth area of $H$. ranunculoides (2 $226.96 \mathrm{~m}^{2}$ ) was $81.53 \%$. While the efficiency of removal of thermotolerant coliforms was $79.2 \%$ at a water temperature of $12.32^{\circ} \mathrm{C}$. Using the operational optimization model in the WWTP with H. ranunculoides, an area of $3291.67 \mathrm{~m}^{2}$ of macrophyte population growth was achieved with a removal efficiency of $93.71 \%$ COD and an area of $3591.67 \mathrm{~m}^{2}$ to remove $79.95 \%$ of the thermotolerant coliforms at a temperature of $13^{\circ} \mathrm{C}$.
\end{abstract}

Keywords: treatment plant, macrophyte, physicochemical parameters, thermotolerant coliforms.

\section{INTRODUCTION}

Water is an essential resource required to conduct human activities and achieve correct development of life [6]. In today's societies, water supply and treatment are the most important issues [16]; still, in practice, less than $20 \%$ of the total wastewater effluents are treated before being discharged into the bodies of water [1]. The treatment of municipal wastewater by public and private sector companies remain as a fundamental priority [7]. Therefore, the demand of good water quality must be met according to the established environmental regulations [8]. There is a wide variety of wastewater treatment systems, from the most sophisticated and modern ones that go at the forefront of technology, to the most artisanal and simple replicated systems of nature [18]; which obtain energy from natural sources, such as aquatic plants [12]. The process of wastewater purification by using aquatic plants or floating macrophytes has been imposed on conventional technology treatments [17]. Natural treatments carried out by unconventional purification systems have demonstrated high rates of efficiency in wastewater treatment [5].

The purification system was developed in the wastewater treatment plant (WWTP) of the Alcas area of the Sicaya district, which is in charge of the Sicaya Peasant Community. According to the records, the WWTP started operation in 2009 without appropriate conditions and kept running during the first two years. However, at the beginning of 2011, the WWTP had been observed for deficiencies in the operation due to the lack of trained personnel and maintenance. In June 2016, through a diagnosis, the WWTP was evaluated in order to correct the deficiencies and start 
it up again to carry out an optimization study of wastewater treatments with the incorporation of macrophytes. In this context, the objective of this study was to optimize the operation of the municipal wastewater treatment plant (WWTP) with the Hydrocotyle ranunculoides macrophyte in the Alcas area of the Sicaya district, Huancayo, Perú.

\section{METHODOLOGY}

\section{Study area}

The study area is located on the right bank of the Mantaro River at $3355 \mathrm{~m}$ asl, north of the city of Huancayo, Junín department in Peru. Its surface extends on the crest of a geological fault, in the middle of the alluvial plains that form a plateau, with a beautiful landscape framed in three staggered sections. The lower section of the district consists of a small forest, the Mantaro River and some springs; the middle section comprises the center of town, where most of the population is concentrated, and the upper section by fertile fields. It has an area of $50 \mathrm{~km}^{2}$, bordered by the district of Orcotuna on the north, the Mantaro River on the east, the district of Pilcomayo and the province of Chupaca on the south as well as the districts of Huachac, Huayao and Aco on the west. Its climate is typical of the Yunga mountain range, varying its environmental temperature in average between $9^{\circ} \mathrm{C}$ and $18^{\circ} \mathrm{C}$ (figure 1).

\section{Pre-experimental part}

In order to evaluate the population growth of the Hydrocotyle ranunculoides, a pre-experiment was developed in order to find the relative growth rate (RGR) of the H. ranunculoides macrophyte, based on the study conducted by Hussner \& Lösch [9]. The calculation was based on the final weight $(\mathrm{Fw})$ and initial weight (Iw) of the biomass [14]. The area (A) of population growth of $H$. ranunculoides had been evaluated, and then the Wf and A relationship was determined. The investigation was performed for ten growth control points (GCP) and area control points (ACP).

\section{Determination of the final weight to determine the relative growth rate}

The assessment of macrophyte growth was based on the growth assessment principles of $H$. ranunculoides from the research of Hussner and Lösch [9]. For this purpose, 10 modules with dimensions of $40 \mathrm{~cm}$ long, $30 \mathrm{~cm}$ wide and $25 \mathrm{~cm}$ deep were used, in which samples of 250 grams of macrophytes $H$. ranunculoides respectively were placed. The $H$. ranunculoides macrophytes from each growth control point were removed every 7 days, these samples were exposed to the sun for three days in order to decrease the amount of water. On the fourth day, it was dried at a temperature of $150^{\circ} \mathrm{C}$ for a period of $24 \mathrm{~h}$.

\section{Determination of the relative growth rate}

The relative growth rate was determined based on the dry weight of the $H$. ranunculoides biomass, through equation 1 [19], where Fw, is the final weight of the biomass; Iw, initial weight of biomass and $t$, time in days.

$$
R G R=\frac{(\ln \mathrm{Fw}-\ln I \mathrm{w})}{\mathrm{t}}
$$
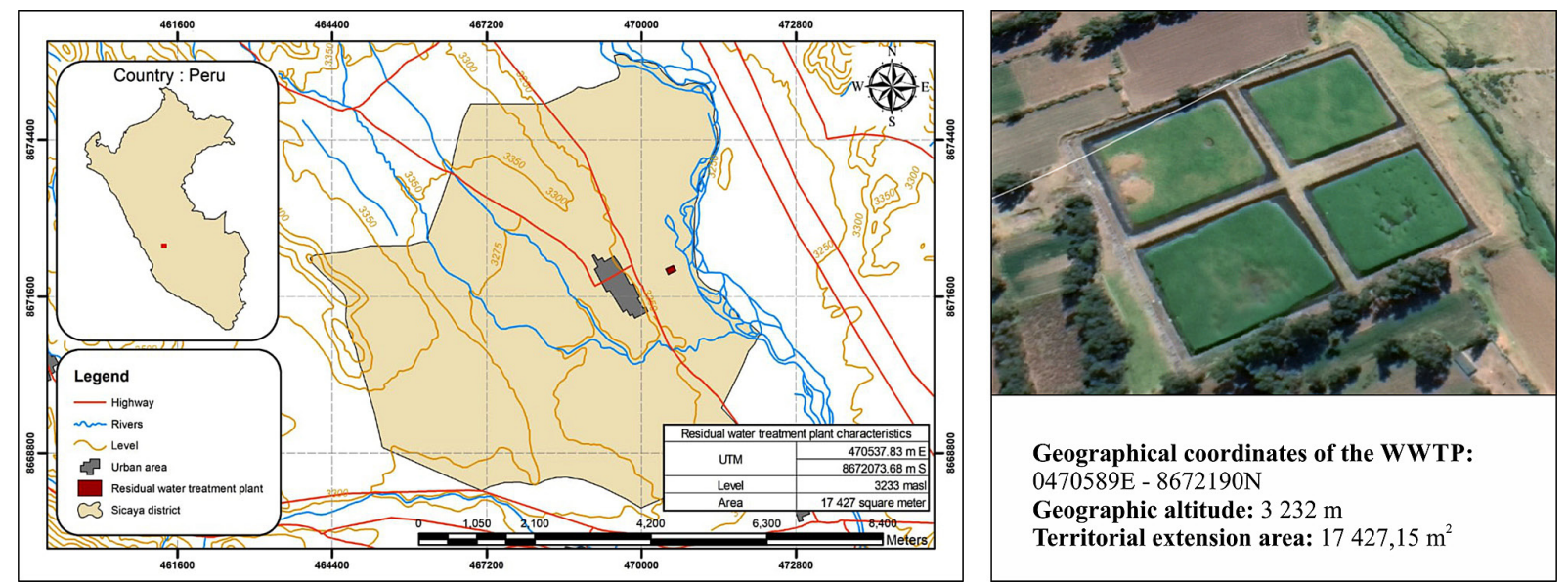

Figure 1. Location of the wastewater treatment plant (WWTP) Alcas - Sicaya 


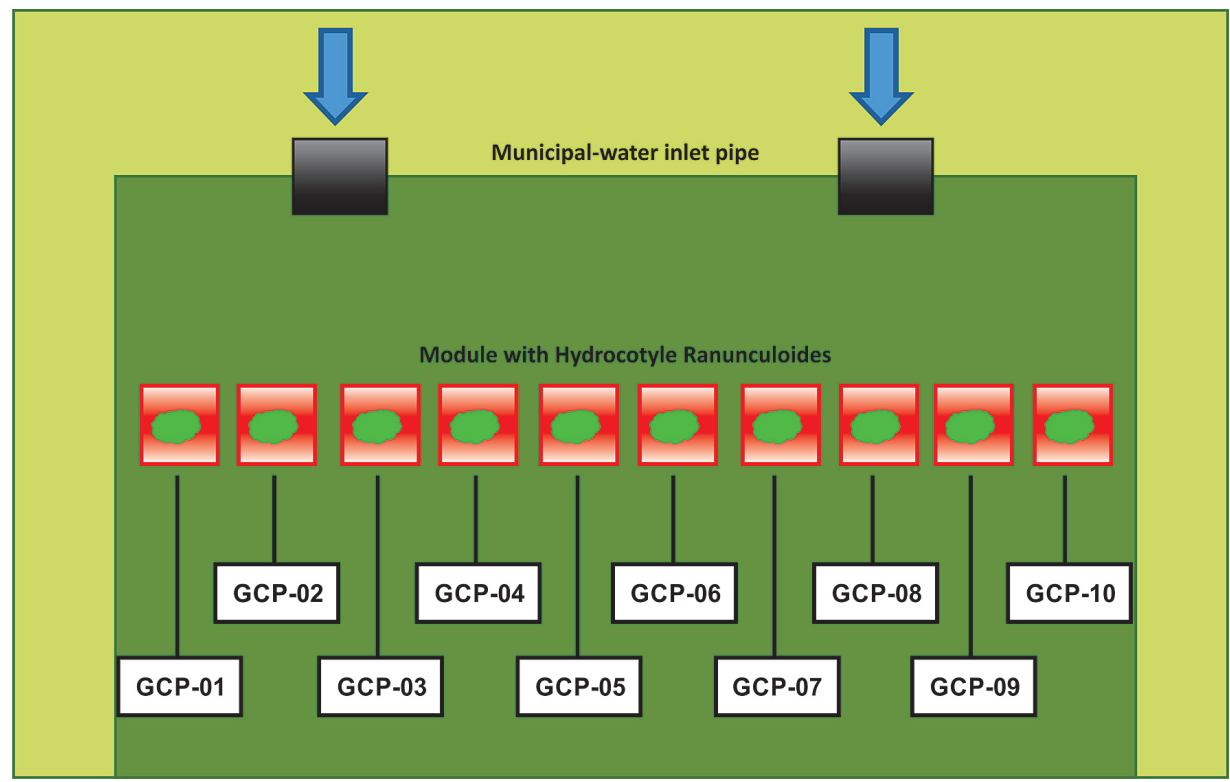

Figure 2. Growth control points of Hydrocotyle ranunculoides macrophytes (GCP-01, GCP-02, GCP-03, GCP-04, GCP-05, GCP-06, GCP-07, GCP-08, GCP-09, y GCP-10)

The initial fresh weight of the macrophytes was $250 \mathrm{~g}$ and dry $7.49 \mathrm{~g}$, for each module. This initial dry weight represents week zero for the ten growth control points (GCP) of the macrophyte, which were weighed every seven days. This methodology was applied so that the adaptation time of macrophytes is not altered [10].

\section{Determination of the final weight from the relative growth rate}

The determination of the final dry weight value of the macrophytes from the growth control points was made from equation 1 from which $\mathrm{Fw}$ is cleared, and thus will be a function of the RGR, initial weight (Iw) and the number of days ( $\mathrm{t}$ ) [4]. The following equation is obtained:

$$
F_{w}=I_{w} * e^{(R G R * t)}
$$

\section{Determination of the population growth area of the macrophyte}

The initial area occupied by the macrophytes in the modules was $30.39 \mathrm{~cm}^{2}$ which corresponds to week zero, the same for the ten area control points (ACP). From the results of the population growth area (A) of the macrophytes, a relation between $\mathrm{Fw}$ and $\mathrm{A}$ was established, from which the macrophyte growth area was determined over a period of 240 days with 30 day intervals in the optional stabilization lagoon of the WWTP of the Alcas area of the Sicaya district.

\section{Experimental part}

\section{Wastewater characterization of the wastewater treatment plant}

The tributary monitoring was according to the protocol for monitoring the effluents of the domestic or municipal wastewater treatment plants, R.M. $\mathrm{N}^{\circ} 273-2013$ - Peru Housing, specifying the point that enters the WWTP, located in the distribution box as point of monitoring 1 (PM-01). The characterization analyses were performed for the following parameters: total suspended solids, BOD, COD, oils and fats, and thermotolerant coliforms.

\section{Implementation of medium bars for the retention of suspended solids}

The implementation of the medium bars was carried out within the channel after the bypass of the preliminary treatment. The design is based on the technical standard OS.090 of wastewater treatment plants.

\section{Determination of the population growth area of the macrophyte Hydrocotyle ranunculoides}

The determination of the population growth area of the macrophyte $H$. ranunculoides in the facultative type stabilization lagoon was obtained from the ratio of the final weight $(\mathrm{Fw})$ and area (A) of the population growth of the macrophyte 
$H$. ranunculoides of the pre-experimental part. The evaluation of the population growth area of this macrophyte was carried out for each stabilization lagoon, this was determined through the calculations made for the RGR determination, in the pre-experimental part.

\section{Wastewater monitoring of the treatment plant}

The sample was taken at two points, the first point is located in the distribution box (PM-01) and the other point at the WWTP discharge before mixing with the waters of the receiving body (PM-02), shown in figure 3. The monitoring period was 240 days between November 2016 and June 2017. The samples were collected in sterile transparent plastic containers of one liter for COD, 250 milliliters for thermotolerant coliforms adding their preserver (thiosulfate 10\%). Once the sampling was finished, they were refrigerated in a cooler with ice pack bags and protected with bubble bags in order to keep the samples for analysis.
The temperature measurement was conducted at each of the monitoring points through the mesh method, based on R.J. 010-2016-ANA. Four monitoring points were established PMT01, PMT-02, PMT-03 and PMT-04, which were monitored one week for each month before the wastewater monitoring, at three times with a fourhour interval: 8:00 12:00 and 16:00 h per day.

\section{Data processing to determine the optimization operation of the wastewater treatment plant}

The optimization of the WWTP is a function of the COD removal efficiency and thermotolerant coliform parameters, for this purpose it was necessary to determine the objective functions that are a function of temperature and population growth area of the macrophytes, thus being the independent variables. Statistical analysis tools (Minitab and Matlab software) were used to evaluate the optimal values of the independent variables.

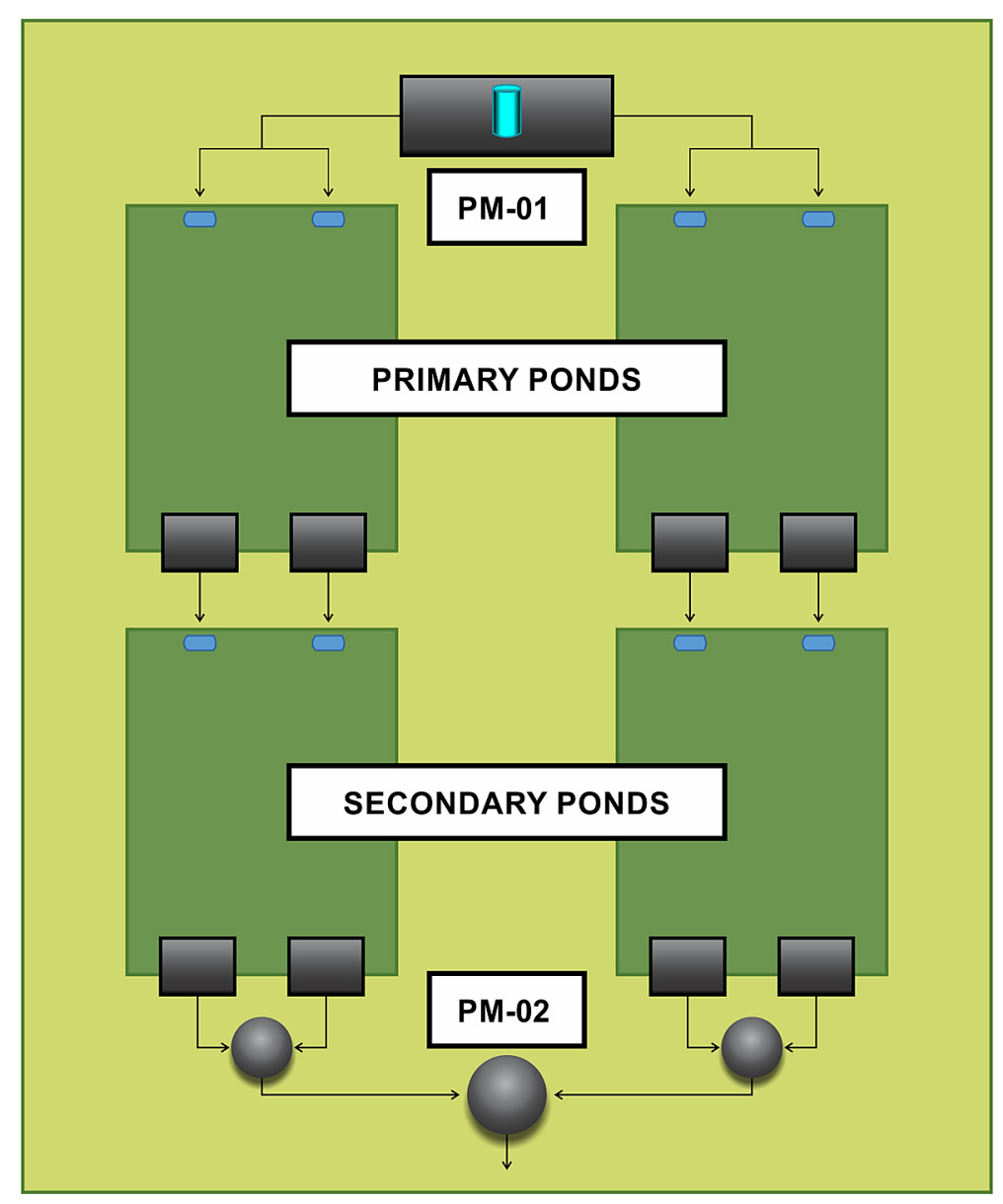

Figure 3. Municipal wastewater sampling points of the wastewater treatment plant 


\section{RESULTS}

\section{Pre-experimental phase}

Determination of the Relative Growth Rate (RGR) of Hydrocotyle ranunculoides

The RGR of macrophyte $H$. ranunculoides was determined at 10 Growth Control Points (GCP) over a period of 70 days, where the final dry weight was calculated in modules every seven days. Table 1 shows the evolution of the growth of the macrophyte biomass.

Next, the RGR of the macrophyte was determined with equation 1 and the data in Table 1. For example, we determined the RGR for 56 days, where the initial dry weight (Iw) is $7.49 \mathrm{~g}$ and the final dry weight (Fw) is $41.80 \mathrm{~g}$ replacing the data we have:

$$
R G R=\frac{(\ln 41.80-\ln 7.49)}{56}=0.0307
$$

Where Iw: dry mass weight at the beginning, $F W$ : dry mass weight at the end in the modules. Finally, the RGR of $H$. ranunculoides was determined obtaining 0.0307 , as shown in Table 2.

\section{Determination of the population growth area of Hydrocotyle ranunculoides}

The population growth area of the Hydrocotyle ranunculoides macrophyte was determined at 10 Area Control Points (ACP) over a period of 70 days over a seven-day interval. Table 3 shows the evolution of the population growth area of the macrophyte.

Table 1. Results of the growth weights of the Hydrocotyle ranunculoides in 70 days

\begin{tabular}{|c|c|c|}
\hline Time (days) & GCP & Final weight $(\mathrm{g})$ \\
\hline 0 & - & 7.49 \\
\hline 7 & GCP-01 & 8.38 \\
\hline 14 & GCP-02 & 9.73 \\
\hline 21 & GCP-03 & 11.92 \\
\hline 28 & GCP-04 & 16.68 \\
\hline 35 & GCP-05 & 21.56 \\
\hline 42 & GCP-06 & 27.10 \\
\hline 49 & GCP-07 & 33.70 \\
\hline 56 & GCP-08 & 41.80 \\
\hline 63 & GCP-09 & 51.90 \\
\hline 70 & GCP-10 & 64.30 \\
\hline
\end{tabular}

Determination of the ratio of final weight and area of Hydrocotyle ranunculoides macrophyte population growth from the modules

From Table 3, equation 3 was determined, which was found through a non-linear regression with the Minitab program, which is as follows:

$$
A=\frac{4563.39 * F w}{1116.51+F w}
$$

\section{Experimental phase}

\section{Wastewater characterization of the Sicaya WWTP}

The characterization of the five main parameters of wastewater that entered the WWTP was carried out.

The characterization of the wastewater entering the Sicaya WWTP revealed that these values are above the environmental quality standards established for the domestic wastewater in discharge sources.

\section{Implementation of medium bars for the retention of suspended solids}

Medium grilles were implemented according to OS.090 technical standard of wastewater treatment plants. The design of the bars was developed with Excel software, in which some considerations were taken, explained in Table 5. The gate chamber that initially had the WWTP of the Alcas site was efficient due to the loss of loading on the bars because of its obstruction resulting from the lack of cleaning, which was very frequent and consequently the lagoons of the WWTP presented large solid waste such as

Table 2. Determination of the RGR of the Hydrocotyle ranunculoides macrophytes

\begin{tabular}{|c|c|c|c|}
\hline Time (days) & Iw $(\mathrm{g})$ & $\mathrm{Fw}(\mathrm{g})$ & RGR \\
\hline 0 & 7.49 & 7.49 & - \\
\hline 7 & 7.49 & 8.38 & 0.0162 \\
\hline 14 & 7.49 & 9.73 & 0.0187 \\
\hline 21 & 7.49 & 11.92 & 0.0221 \\
\hline 28 & 7.49 & 16.68 & 0.0286 \\
\hline 35 & 7.49 & 21.56 & 0.0302 \\
\hline 42 & 7.49 & 27.10 & 0.0306 \\
\hline 49 & 7.49 & 33.70 & 0.0307 \\
\hline 56 & 7.49 & 41.80 & 0.0307 \\
\hline 63 & 7.49 & 51.90 & 0.0307 \\
\hline 70 & 7.49 & 64.30 & 0.0307 \\
\hline
\end{tabular}


Table 3. Results of the area control of Hydrocotyle ranunculoides macrophyte population growth

\begin{tabular}{|c|c|c|}
\hline Time (days) & ACP & $\mathrm{A}\left(\mathrm{cm}^{2}\right)$ \\
\hline 0 & - & 30.39 \\
\hline 7 & ACP-01 & 34.01 \\
\hline 14 & ACP-02 & 38.97 \\
\hline 21 & ACP-03 & 48.19 \\
\hline 28 & ACP-04 & 67.16 \\
\hline 35 & ACP-05 & 86.44 \\
\hline 42 & ACP-06 & 108.14 \\
\hline 49 & ACP-07 & 133.70 \\
\hline 56 & ACP-08 & 164.68 \\
\hline 63 & ACP-09 & 202.70 \\
\hline 70 & ACP-10 & 248.50 \\
\hline
\end{tabular}

Table 4.Characterization of the tributary of the WWTP during the development of the project

\begin{tabular}{|l|c|}
\hline \multicolumn{1}{|c|}{ Sample identification } & PM-01 \\
\hline Total solids $(\mathrm{mg} / \mathrm{l})$ & 616 \\
\hline $\mathrm{BOD}_{5}(\mathrm{mg} / \mathrm{l})$ & 109.2 \\
\hline $\mathrm{COD}(\mathrm{mg} / \mathrm{l})$ & 305.40 \\
\hline Oils and fats $(\mathrm{mg} / \mathrm{l})$ & 30.3 \\
\hline $\begin{array}{l}\text { Numbering of Thermotolerant Coliforms } \\
\text { (NMP/100ml) }\end{array}$ & 3500000 \\
\hline
\end{tabular}

Source: SGS Laboratory of Perú

bottles, diapers, inorganic remains, etc., making it difficult to treat the municipal wastewater. When the grating chamber was implemented, the large suspended solids were removed.

\section{Population growth area of Hydrocotyle ranunculoides with the removal efficiency of organic matter and thermotolerant coliforms}

Table 6 shows the results of the COD and thermotolerant coliforms (TC) parameters obtained every thirty days. The highest COD removal efficiency with respect to the growth area of $H$. ranunculoides $\left(2226.96 \mathrm{~m}^{2}\right.$ ) was $81.53 \%$. These results are very close to those obtained by Kouki and others [11] who reported that the COD removal efficiency was $89 \%$. This is due to the type of debugging treatment each system has. In the present study, the treatment was performed in facultative type stabilization lagoons with the Hydrocotyle ranunculoides, in contrast with the other study that was carried out in wetland modules with macrophytes Phragmites australis and Typha orientalis [20]. Nevertheless, it should be noted that there are macrophytes with a higher percentage of organic matter purification than others, according to the studies and experiments carried out [12].
Table 5. Design parameters of medium bars

\begin{tabular}{|c|c|}
\hline Parameters & Dimensions \\
\hline$Q_{\min }$ & $0.013 \mathrm{~m}^{3} / \mathrm{s}$ \\
\hline$Q_{\text {prom }}$ & $0.022 \mathrm{~m}^{3} / \mathrm{s}$ \\
\hline $\mathrm{Q}_{\text {máx }}(\mathrm{Q})$ & $0.0258 \mathrm{~m}^{3 / \mathrm{s}}$ \\
\hline Inclination angle: $\mathrm{OS}-090<45^{\circ}-60^{\circ}>$ & $60^{\circ}$ \\
\hline Bar thickness (e) & $0.0075 \mathrm{~m}$ \\
\hline Bar spacing (a) & $0.026 \mathrm{~m}$ \\
\hline Bar efficiency $E=(a /(e+a))$ & 0.78 \\
\hline Approach speed (Vo) $<0.3-0.6>$ & $0.50 \mathrm{~m} / \mathrm{s}$ \\
\hline Channel Width (b) (measured in field) & $0.40 \mathrm{~m}$ \\
\hline Number of bars & 14 \\
\hline
\end{tabular}

Regarding the removal efficiency of thermotolerant coliforms in the area of $2226.96 \mathrm{~m}^{2}$ the population growth of $H$. ranunculoides macrophytes was $79.20 \%$; which indicates that macrophytes are highly efficient with respect to the removal of this parameter, while in the study by Sartori et al. [15] who worked with constructed wetlands, a greater removal efficiency of $99.0 \%$ was achieved; this results from the different treatment systems that are used which differ in respect to their ability to remove of each macrophyte influenced by the meteorological variations [13].

The obtained results were processed with Excel for 240 days, measured seven days prior to the municipal wastewater analysis. From the monitored temperatures, it is observed that the removal efficiency of COD and thermotolerant coliforms are affected. When the temperature rises, the removal rate for both parameters increases [3]. Nevertheless, the highest percentage of removal of COD and thermotolerant coliforms was at an average temperature of $12.32^{\circ} \mathrm{C}$, as shown in Table 7. This means that at a higher temperature there is a higher percentage of removal, but it can be seen that it tends to decrease at the sixth and seventh sampling due to the limited capacity of macrophyte development. Initially seeded

Table 6. COD removal efficiency of the WWTP, every thirty days

\begin{tabular}{|c|c|c|c|}
\hline Days & Area & $\begin{array}{c}\% \text { COD } \\
\text { Removal }\end{array}$ & $\begin{array}{c}\% \text { CT } \\
\text { Removal }\end{array}$ \\
\hline 30 & 106.58 & 45.00 & 45.00 \\
\hline 60 & 259.07 & 60.00 & 50.30 \\
\hline 90 & 599.00 & 73.72 & 52.45 \\
\hline 120 & 1255.35 & 79.07 & 53.80 \\
\hline 150 & 2226.96 & 81.53 & 79.20 \\
\hline 180 & 3218.91 & 81.27 & 78.17 \\
\hline 210 & 3912.75 & 80.63 & 78.00 \\
\hline 240 & 4280.04 & 75.00 & 77.37 \\
\hline
\end{tabular}


Table 7. Municipal wastewater temperatures and the removal efficiency of COD and thermotolerant coliforms (TC)

\begin{tabular}{|c|c|c|}
\hline $\mathrm{T}\left({ }^{\circ} \mathrm{C}\right)$ & \% COD Removal & \% CT Removal \\
\hline 9.67 & 45.00 & 45.00 \\
\hline 10.00 & 60.00 & 50.30 \\
\hline 11.50 & 73.72 & 52.45 \\
\hline 12.17 & 79.07 & 53.80 \\
\hline 12.32 & 81.53 & 79.20 \\
\hline 13.03 & 81.27 & 78.17 \\
\hline 13.10 & 80.63 & 78.00 \\
\hline 13.20 & 75.00 & 77.37 \\
\hline
\end{tabular}

macrophytes have a high reproductive life cycle of five to six months, later this cycle is reduced due to the limited area for the expansion of nascent macrophytes.

\section{Determination of the optimization of the} removal efficiency of $C O D$ and thermotolerant coliforms in the wastewater treatment plant

The process of optimizing the operation of the WWTP is based on the efficiency of COD and thermotolerant coliforms removal based on the temperature and population growth area of $H$. ranunculoides. For this purpose, the optimization equation was determined with the monitored data shown in Table 8, using the Minitab and Matlab Software.
Table 8. Temperature, growth area of Hydrocotyle ranunculoides and percentage of COD removal and thermotolerant coliforms (TC)

\begin{tabular}{|c|c|c|c|}
\hline $\mathrm{T}\left({ }^{\circ} \mathrm{C}\right)$ & Area $\left(\mathrm{m}^{2}\right)$ & $\begin{array}{c}\% \text { COD } \\
\text { Removal }\end{array}$ & $\begin{array}{c}\% \mathrm{TC} \\
\text { Removal }\end{array}$ \\
\hline 9.67 & 106.58 & 45.00 & 45.00 \\
\hline 10.00 & 259.07 & 60.00 & 50.30 \\
\hline 11.50 & 599.00 & 73.72 & 52.45 \\
\hline 12.17 & 1255.35 & 79.07 & 53.80 \\
\hline 12.32 & 2226.96 & 81.53 & 79.20 \\
\hline 13.03 & 3218.91 & 81.27 & 78.17 \\
\hline 13.10 & 3912.75 & 80.63 & 78.00 \\
\hline 13.20 & 4280.04 & 75.00 & 77.37 \\
\hline
\end{tabular}

With the data in Table 8 (temperature, growth area of $H$. ranunculoides and percentage of COD and TC removal), linear regression was developed in the Minitab software, where the following equations were obtained:

$$
\begin{gathered}
\% \boldsymbol{R C O D}=-1465+280 * T-0.149 * A+ \\
+0.0145 * T * A-12.7 * T^{2}-0.000006 * A^{2} \\
\% \text { RCol. Ter. }=-1794+358 * T- \\
-0.205 * A+0.0224 * T * A- \\
-17.38 * T^{2}-0.000012 * A^{2}
\end{gathered}
$$

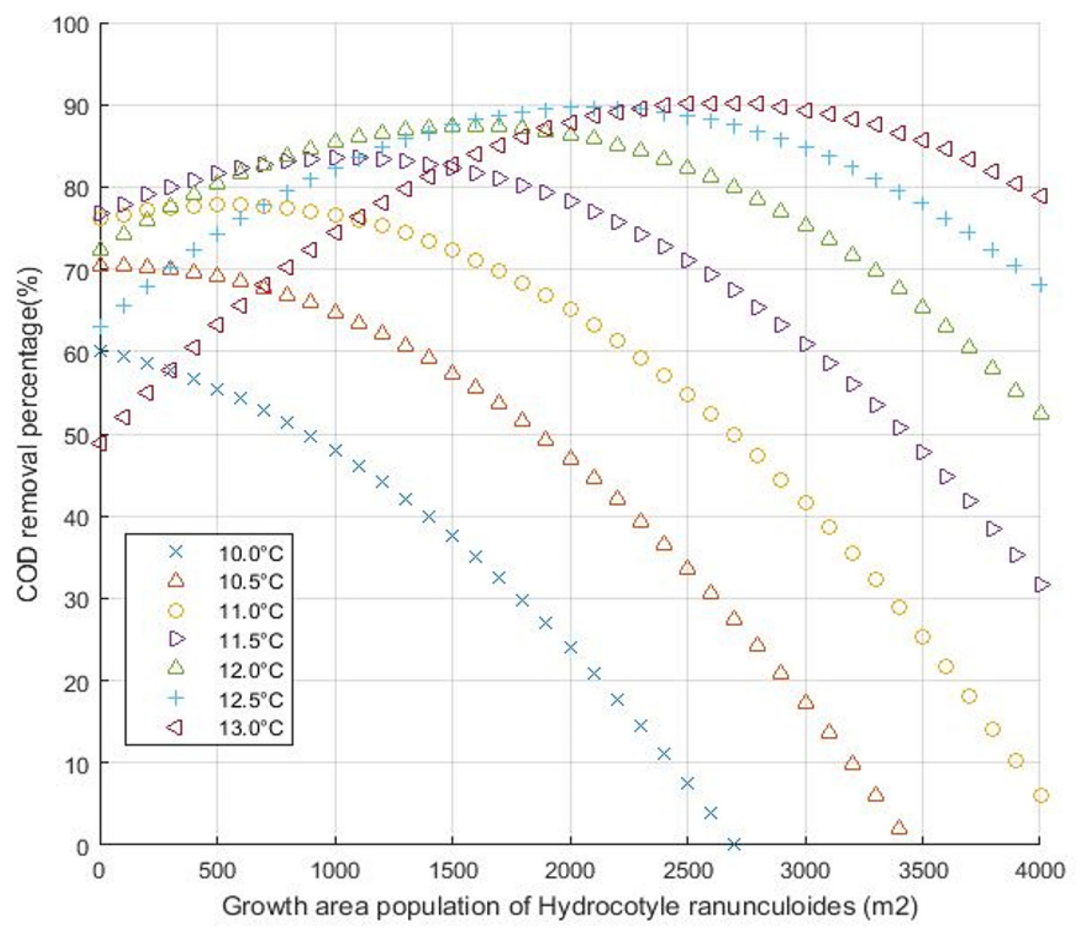

Figure 4. Optimization lines of COD removal percentage at different temperatures 


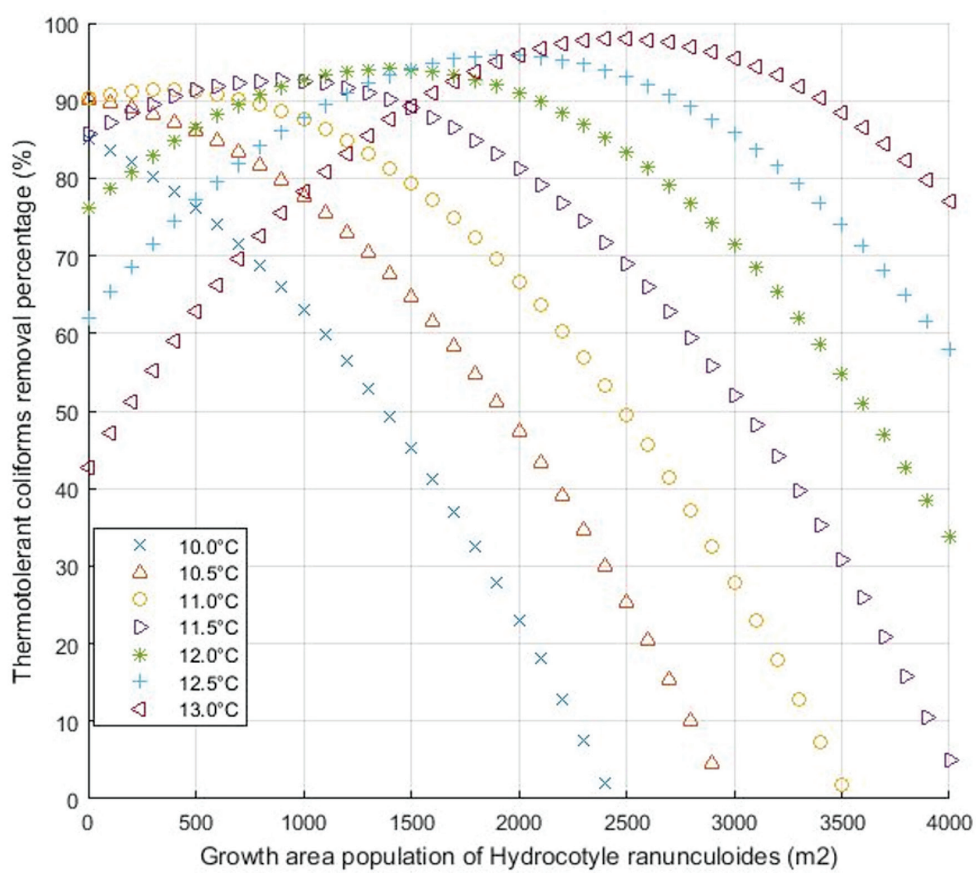

Figure 5. Optimization lines for percentage removal of thermotolerant coliforms

Then, using the Matlab software the optimization lines evaluated at different temperatures were determined from equations 4 and 5 , as shown in Figures 4 and 5. From Figure 4, it can be affirmed that the optimal percentage of COD removal is $93.71 \%$, which is achieved with a population growth area of the $H$. ranunculoides macrophyte of $3291.67 \mathrm{~m}^{2}$ at a temperature of $13^{\circ} \mathrm{C}$. On the other hand, according to Figure 5, we affirm that the optimal percentage of removal of thermotolerant coliforms is achieved with a population growth area of the macrophyte of $3591.67 \mathrm{~m}^{2}$ at a temperature of $13^{\circ} \mathrm{C}$.

\section{CONCLUSIONS}

The municipal wastewater treatment plant in the Alcas area of the Sicaya district, Huancayo, implemented with the Hydrocotyle ranunculoides macrophyte, demonstrated a COD removal efficiency of $81.53 \%$ and $79.2 \%$ thermotolerant coliforms, evaluated at a temperature of $12.32^{\circ} \mathrm{C}$.

The optimization model for the prediction of COD removal efficiency resulted in $93.71 \%$ for a population growth area of the macrophyte of 3 $291.67 \mathrm{~m}^{2}$. On the other hand, the prediction of the efficiency of removal of thermotolerant coliforms was $79.95 \%$ for a population growth area of the macrophyte of $3591.67 \mathrm{~m}^{2}$. Both optimization models were evaluated for a temperature of $13^{\circ} \mathrm{C}$.

\section{REFERENCES}

1. Alvarez-Mieles G., Irvine K., Griensven A. V., AriasHidalgo M., Torres A., Mynett A. E. 2013. Relationships between aquatic biotic communities and water quality in a tropical river-wetland system (Ecuador). Environmental Science and Policy, 34, 115-127. https://doi.org/10.1016/j.envsci.2013.01.011.

2. Alvarez M., Luque L., Bustamante E. 2012. Humedales de la yunga amazónica en los departamentos Huánuco y San Martín, Perú. ECIPERÚ, (June 2009).

3. Barko J. W., Hardin D. G., Matthews M. S. 2007. Growth and morphology of submersed freshwater macrophytes in relation to light and temperature. Canadian Journal of Botany. https://doi. org/10.1139/b82-113.

4. Barrera J., Melgarejo L. M. 2006. Análisis De Crecimiento En Plantas. In Experimentos en fisiologíay bioquímica vegetal.

5. Caviedes Rubio D. I., Delgado D. R., Olaya Amaya A. 2016. Remoción de metales pesados comúnmente generados por la actividad industrial, empleando macrófitas neotropicales. Producción + Limpia, 11(2), 126-149. https://doi.org/10.22507/ pml.v11n2a11.

6. Custodio M., Peñaloza R., Chanamé F., Yaranga R., Pantoja R. 2018. Assessment of the Aquatic Environment Quality of High Andean Lagoons using Multivariate Statistical Methods in Two Contrasting Climatic Periods. Journal of Ecological Engineering, 19(6), 24-33. https://doi. org/10.12911/22998993/92677. 
7. Eda L. E. H., Chen W. 2010. Integrated water resources management in Peru. In Procedia Environmental Sciences. https://doi.org/10.1016/j.proenv.2010.10.039.

8. EPA. 2019. Water Quality Criteria. Retrieved from https://www.epa.gov/wqc.

9. Hussner A., Lösch R. 2007. Growth and photosynthesis of Hydrocotyle ranunculoides L. fil. in Central Europe. Flora: Morphology, Distribution, Functional Ecology of Plants. https://doi.org/10.1016/j. flora.2007.05.006.

10. Hussner A., Meyer C. 2009. The influence of water level on the growth and photosynthesis of Hydrocotyle ranunculoides L.fil. Flora: Morphology, Distribution, Functional Ecology of Plants. https://doi. org/10.1016/j.flora.2008.10.005.

11. Kouki S., M'hiri F., Saidi N., Belaïd S., Hassen A. 2009. Performances of a constructed wetland treating domestic wastewaters during a macrophytes life cycle. Desalination. https://doi.org/10.1016/j. desal.2008.03.067.

12. Leto C., Tuttolomondo T., La Bella S., Leone R., Licata M. 2013. Growth of Arundo donax L. and Cyperus alternifolius L. in a horizontal subsurface flow constructed wetland using pre-treated urban wastewater-a case study in Sicily (Italy). Desalination and Water Treatment. https://doi.org/10.1080/ 19443994.2013.792134.

13. Mustapha H. I., Van Bruggen J. J. A., Lens P. N. L. 2015. Vertical subsurface flow constructed wetlands for polishing secondary Kaduna refinery wastewater in Nigeria. Ecological Engineering. https://doi.org/10.1016/j.ecoleng.2015.09.060.

14. Paine C. E. T., Marthews T. R., Vogt D. R., Purves D., Rees M., Hector A., Turnbull L. A. 2012. How to fit nonlinear plant growth models and calculate growth rates: An update for ecologists. Methods in Ecology and Evolution. https://doi.org/10.1111/ j.2041-210X.2011.00155.X.

15. Sartori L., Canobbio S., Fornaroli R., Cabrini R., Marazzi F., Mezzanotte V. 2016. COD, nutrient removal and disinfection efficiency of a combined subsurface and surface flow constructed wetland: A case study. International Journal of Phytoremediation. https://doi.org/10.1080/15226514.2015.11 09601.

16. Şener Ş., Şener E., Davraz A. 2017. Evaluation of water quality using water quality index (WQI) method and GIS in Aksu River (SW-Turkey). Science of the Total Environment. https://doi. org/10.1016/j.scitotenv.2017.01.102.

17. Vergeles Y., Vystavna Y., Ishchenko A., Rybalka I., Marchand L., Stolberg F. 2015. Assessment of treatment efficiency of constructed wetlands in East Ukraine. Ecological Engineering. https://doi. org/10.1016/j.ecoleng.2015.06.020.

18. Wu H., Zhang J., Ngo H. H., Guo W., Hu Z., Liang S., Liu H. 2015. A review on the sustainability of constructed wetlands for wastewater treatment: Design and operation. Bioresource Technology. https://doi.org/10.1016/j.biortech.2014.10.068.

19. Yakup Onur K. 2016. Changes of dry matter, biomass and relative growth rate with different phenological stages of corn. ScienceDirect, 10, 67-75. Retrieved from https:/www.sciencedirect.com/science/article/pii/S221078431630208X.

20. Zheng Y., Wang X. C., Dzakpasu M., Ge Y., Zhao Y., Xiong J. 2016. Performance of a pilot demonstration-scale hybrid constructed wetland system for on-site treatment of polluted urban river water in Northwestern China. Environmental Science and Pollution Research. https://doi.org/10.1007/ s11356-015-5207-y. 